\title{
Geophysical validation and long-term consistency between GOME-2/MetOp-A total ozone column and measurements from the sensors GOME/ERS-2, SCIAMACHY/ENVISAT and OMI/Aura
}

\author{
M. E. Koukouli ${ }^{1}$, D. S. Balis ${ }^{1}$, D. Loyola ${ }^{2}$, P. Valks ${ }^{2}$, W. Zimmer ${ }^{2}$, N. Hao ${ }^{2}$, J.-C. Lambert ${ }^{3}$, M. Van Roozendael ${ }^{3}$, \\ C. Lerot $^{3}$, and R. J. D. Spurr ${ }^{4}$ \\ ${ }^{1}$ Laboratory of Atmospheric Physics, Aristotle University of Thessaloniki, Thessaloniki, Greece \\ ${ }^{2}$ Deutsches Zentrum für Luft- und Raumfahrt (DLR), Institut für Methodik der Fernerkundung (IMF), \\ 82234 Oberpfaffenhofen, Germany \\ ${ }^{3}$ Belgian Institute for Space Aeronomy (BIRA-IASB), 3, Avenue Circulaire, 1180 Brussels, Belgium \\ ${ }^{4}$ RT-Solutions, Inc., Cambridge, MA, USA \\ Correspondence to: M. E. Koukouli (mariliza@auth.gr)
}

Received: 22 March 2012 - Published in Atmos. Meas. Tech. Discuss.: 24 April 2012

Revised: 20 July 2012 - Accepted: 23 July 2012 - Published: 7 September 2012

\begin{abstract}
The main aim of the paper is to assess the consistency of five years of Global Ozone Monitoring Experiment2/Metop-A [GOME-2] total ozone columns and the longterm total ozone satellite monitoring database already in existence through an extensive inter-comparison and validation exercise using as reference Brewer and Dobson groundbased measurements. The behaviour of the GOME-2 measurements is being weighed against that of GOME (19952011), Ozone Monitoring Experiment [OMI] (since 2004) and the Scanning Imaging Absorption spectroMeter for Atmospheric CartograpHY [SCIAMACHY] (since 2002) total ozone column products. Over the background truth of the ground-based measurements, the total ozone columns are inter-evaluated using a suite of established validation techniques; the GOME-2 time series follow the same patterns as those observed by the other satellite sensors. In particular, on average, GOME-2 data underestimate GOME data by about $0.80 \%$, and underestimate SCIAMACHY data by $0.37 \%$ with no seasonal dependence of the differences between GOME-2, GOME and SCIAMACHY. The latter is expected since the three datasets are based on similar DOAS algorithms. This underestimation of GOME- 2 is within the uncertainty of the reference data used in the comparisons. Compared to the OMI sensor, on average GOME-2 data underestimate OMI_DOAS (collection 3) data by $1.28 \%$, without any significant seasonal dependence of the differ-
\end{abstract}

ences between them. The lack of seasonality might be expected since both the GOME data processor [GDP] 4.4 and OMI_DOAS are DOAS-type algorithms and both consider the variability of the stratospheric temperatures in their retrievals. Compared to the OMI_TOMS (collection 3) data, no bias was found. We hence conclude that the GOME-2 total ozone columns are well suitable to continue the longterm global total ozone record with the accuracy needed for climate monitoring studies.

\section{Introduction}

With the launch of Metop-A on 19 October 2006, a polar orbiting satellite carrying both environmental and meteorological instruments, a new global total ozone data record was started with the GOME-2 instrument. In Loyola et al. (2011), the GOME data processor (GDP) version 4.4 retrieval algorithm for GOME-2 total ozone, as well as the first global validation results for three years (2007-2009) using Brewer and Dobson ground-based measurements, was described. Several algorithm improvements were introduced in GDP $4.4 \mathrm{com}$ pared to previous versions (van Roozendael et al., 2006) such as the improved cloud retrieval algorithms including the discrimination of sun-glint effects, the enhanced treatment for ice and snow conditions, the intra-cloud ozone correction,

Published by Copernicus Publications on behalf of the European Geosciences Union. 
the updated radiative transfer modelling for large viewing angle conditions and the empirical correction to eliminate a scan angle dependency caused by an unknown bias. To be precise, the forward-scan west-east dependency of more than $+1.5 \%$ in the previous GDP 4.x data has been largely eliminated in the GDP 4.4 record. The GDP 4.4 algorithm is able enough to deliver real-time data for operational needs while being truly robust in performance. As far as the validation was concerned, for middle latitude comparisons, Loyola et al. (2011) already showed that the reprocessed GOME-2 GDP 4.4 dataset underestimates ground-based Dobson ozone by $0.5 \%$ in the Northern Hemisphere, whereas it overestimates in the Southern Hemisphere by the same amount. For northern high latitude comparisons, a good comparison relative to the Dobson measurement is found, while, for the southern high latitude comparisons, an underestimation of less than $1 \%$ is observed. For the tropical stations, GOME-2 underestimates on average by 0 to $2 \%$ against the Dobson network. The GOME-2 versus Brewer comparisons over the Northern Hemisphere follow closely the GOME-2 vs. Dobson comparisons and illustrate an underestimation of $1 \%$ which tends to be slightly higher (1-2\%) over the Arctic.

Equally important to the stand-alone validation and quality assurance of new atmospheric composition products is to ensure the continuity in the record between current and past missions. Even though the processors analysing the atmospheric signal might be the same, even slight differences in spectral and spatial resolution, detector technology, swath width, and other characteristics might bring notable differences between the resulting total ozone products from different sensors. In the following, we will delve into the comparisons between GOME- 2 total ozone for the years 2007 to 2010 against other three satellite instruments active during this time period, using as reference a background of groundbased total ozone measurements. In Sect. 2 we discuss the different datasets used with some details on both instruments and algorithms given as well as known issues with the total ozone records, as these were recorded in literature. In Sect. 3 we show the results and the discussion, with the summary and conclusions given in Sect. 4.

\section{Datasets and methodology}

\subsection{The four satellite instruments}

A very brief description of the four different instruments and the relevant algorithms is given in this following section. For quick reference to the information, the main features of the four instruments, satellite platforms and data versions used in this study are further summarized in Table 1.

\subsubsection{GOME on board ERS-2}

The Global Ozone Monitoring Experiment (GOME) is an across-track nadir-viewing spectrometer on board ERS-2 which is a Sun-synchronous polar orbiting satellite with a period of about $100 \mathrm{~min}$ and a local Equator crossing time of 10:30 LT. In normal viewing mode, GOME performs three forward scans followed by a backward scan. Each forward scan has a footprint size of $320 \mathrm{~km} \times 40 \mathrm{~km}$ for a 1.5 -s detector readout integration time. The maximum swath is $960 \mathrm{~km}$, with nominal scan angle $\pm 31^{\circ}$ at the spacecraft, and global coverage is achieved at the Equator within three days. GOME has 3584 spectral channels distributed over four serial readout detectors; the wavelength range is 240 to $793 \mathrm{~nm}$, with a moderate spectral resolution of 0.2 to $0.4 \mathrm{~nm}$. More details on the GOME instrument are given by Burrows et al. (1999a). The instrument was switched off on 5 July 2011 when the ERS-2 satellite was decommissioned. The GOME total ozone columns presented in this work here are the operational GDP 4.1 products (Van Roozendael et al., 2006). Known issues with the GOME total ozone columns reported in Balis et al. (2007a) include a small mean seasonal dependence remaining north of $40^{\circ} \mathrm{N}$ and south of $40^{\circ} \mathrm{S}$. The amplitude of this seasonality does not exceed $1 \%-1.5 \%$ for the Dobson comparisons and is even less for the Brewer comparisons. Also, there is an overestimation of GOME for SZA (solar zenith angles) between $60^{\circ}$ and $70^{\circ}$, and a reversal of the SZA trend at $75^{\circ}$ for the GDP 4.1/Dobson comparisons. The total column products do not suffer from any long-term drift of quality from 1995 to 2003, despite instrument degradation; the stability of the GDP 4.1 ozone data record enables it to be used confidently for ozone trend monitoring.

\subsubsection{SCIAMACHY on board ENVISAT}

The Scanning Imaging Absorption spectroMeter for Atmospheric CartograpHY (SCIAMACHY) was launched in March 2002 aboard the European platform ENVISAT and has been operational for more than ten years providing global coverage in approximately six days (Bovensmann et al., 1999). ENVISAT is in a Sun-synchronous orbit with an inclination of $98.5^{\circ}$, a mean altitude of $796 \mathrm{~km}$ and has a period of $100 \mathrm{~min}$, performing about 14 to 15 orbits per day. SCIAMACHY is an eight-channel spectrometer covering the spectral range from $240 \mathrm{~nm}$ to $2380 \mathrm{~nm}$ and uses different viewing geometries for retrieving total trace gas columns (nadir) and profiles (limb and solar/lunar occultation). The nominal swath is $960 \mathrm{~km}$ with a typical footprint size of $60 \mathrm{~km} \times 30 \mathrm{~km}$ for ozone observations; global coverage is achieved at the Equator within six days. The total ozone column data used in this study are from the SCIAMACHY differential optical absorption spectroscopy (SDOAS) algorithm, which is the prototype algorithm for GOME(-2) and SCIAMACHY operational products GDP4.x and SGP5.0, with details found in Lerot et al. (2009). With respect to ground-based data on the whole, there is no appreciable systematic bias and more than $75 \%$ of the measurements used in this paper agree within $5 \%$ for the set of ground stations used in Lerot et al. (2009). It is also important to 
Table 1. Main characteristics of the GOME-2/MetOp GOME/ERS-2, SCIAMACHY and OMI instruments relevant to the total ozone column products.

\begin{tabular}{|c|c|c|c|c|}
\hline & GOME/ERS-2 & SCIAMACHY & OMI & GOME-2/MetOp \\
\hline Principle & UV/VIS grating spectrometer & UV/VIS/NIR grating spectrometer & UV/VIS grating spectrometer & UV/VIS grating spectrometer \\
\hline Detectors & Reticon linear diode array & Reticon linear diode array & 2-dimensional CCD & Reticon linear diode array \\
\hline Spectral resolution & $0.20 \mathrm{~nm}$ & $0.26 \mathrm{~nm}$ & $0.45 \mathrm{~nm}$ & $0.26 \mathrm{~nm}$ \\
\hline $\begin{array}{l}\text { Spatial resolution } \\
\text { (default) }\end{array}$ & $320 \times 40 \mathrm{~km}^{2}$ & $60 \times 30 \mathrm{~km}^{2}$ & Up to $13 \times 24 \mathrm{~km}^{2}$ & $80 \times 40 \mathrm{~km}^{2}$ \\
\hline Swath width & $960 \mathrm{~km}$ & $960 \mathrm{~km}$ & $2600 \mathrm{~km}$ & $1920 \mathrm{~km}$ \\
\hline Dataset span & 1995-2011 & 2002-2011 & 2004-2011 & 2007-2011 \\
\hline Eq. crossing time & 10:30 LT & 10:00 LT & 13:30 LT & 09:30 LT \\
\hline Level-0-to-1b alg. & GDP L01 4.0 & IPF 6.03 & OML1BRUG (v003) & GOME-2 PPF 4.x \\
\hline Level-1-to-2 alg. & GDP 4.1 & SDOAS (SGP 5.0) & $\begin{array}{l}\text { OMDOAO3 v1.0.5 } \\
\& \text { OMTO3 v1.1.0 }\end{array}$ & GDP 4.4 \\
\hline
\end{tabular}

* In addition to the parameters listed here, the differential signal-to-noise characteristics of the instruments can have an impact on the total ozone column retrieval as well.

note that the SCIAMACHY total $\mathrm{O}_{3}$ columns suffer from a small but statistically significant decreasing trend, ranging between -0.20 and $-0.50 \%$ per annum. The issue is related to the well-known instrumental degradation of SCIAMACHY which generates time-dependent spectral features in the measured reflectances and introduces an artificial trend in the ozone total columns.

\subsubsection{OMI on board aura}

The Ozone Monitoring Instrument (OMI) (Levelt et al., 2006) is one of four instruments aboard the NASA EOS-Aura satellite, launched on 15 July 2004 (Schoeberl et al., 2006). OMI is a compact nadir-viewing, wide swath (daily global coverage), ultraviolet-visible $(270 \mathrm{~nm}$ to $500 \mathrm{~nm})$ imaging spectrometer that was contributed to the Aura mission by the Netherlands and Finland. The foot pixel size at nadir is $13 \mathrm{~km} \times 25 \mathrm{~km}$. In contrast to GOME and SCIAMACHY, the foot pixel size is not constant but increases for the off-nadir positions. Two total ozone column data products are available: the OMI-TOMS data product, which is based on the long-standing TOMS V8 retrieval algorithm (Bhartia et al., 2004); and the OMI-DOAS data product, which is a DOAS type algorithm (Veefkind et al., 2006) developed by the Royal Netherlands Meteorological Institute (KNMI). Balis et al. (2007b) have shown that, although both algorithms infer total ozone column data for OMI ground pixels, they differ in many aspects of their algorithmic approach and this is reflected in the validation and comparison campaigns. Balis et al. (2007b), showed a globally averaged agreement of better than $1 \%$ for OMI-TOMS data and better than $2 \%$ for OMI-DOAS data with the ground-based observations. The OMI-TOMS data product was found to be of high overall quality with no significant dependence on solar zenith angle or latitude. The OMI-DOAS data product had no significant dependence on latitude except for the high latitudes of the Southern Hemisphere, where it systematically overestimated the total ozone value. In addition, a significant dependence on solar zenith angle is found between OMI-DOAS and ground- based data. In this work, both products will be considered and were extracted from the Aura Validation Data Centre (http: //avdc.gsfc.nasa.gov/). The OMI_TOMS and OMI_DOAS level-2 total ozone data are based on collection 3 level $1 \mathrm{~b}$ data and have been processed with TOMS v8.5 and OMDOAO3 v1.0.1 algorithms respectively (see ATBD documents at http://toms.gsfc.nasa.gov and http://www.temis.nl). The well-known "OMI row anomaly" issue, which affects particular viewing directions that correspond to rows on the CCD detector, has been dealt with by discarding observations with the equivalent quality flag as discussed in detail at http://www.knmi.nl/omi/research/product/index.php.

\subsubsection{GOME-2 on board MetOp-A}

The Global Ozone Monitoring Experiment-2 (GOME-2) instrument is mounted on the flight-direction side of the MetOp-A satellite. GOME-2 is a nadir-viewing scanning spectrometer, with an across-track scan time of $6 \mathrm{~s}$ and a swath width of $1920 \mathrm{~km}$. Global coverage of the sunlit part of the atmosphere can be achieved almost within one day. GOME-2 ground pixels have a footprint size of $80 \mathrm{~km} \times 40 \mathrm{~km}$, four times smaller than those for GOME $(320 \mathrm{~km} \times 40 \mathrm{~km})$, and also improved polarisation monitoring and calibration capabilities (Munro et al., 2006). In the framework of EUMETSAT's Satellite Application Facility on Ozone and Atmospheric Chemistry Monitoring (O3MSAF), GOME-2 total ozone data are processed at DLR operationally, both in near-real time and offline, using the GDP 4.x algorithm (Valks et al., 2011). However, operational data were based on different versions of level $1 \mathrm{~b}$ data, and in addition, the satellite measurements showed a scan angle dependency. In order to provide a homogeneous dataset, the complete GOME-2 dataset was reprocessed with GDP 4.4 at the end of 2009 using the most recent level $1 \mathrm{~b}$ data (version 4), plus an additional empirical correction for the east-west scan dependencies as described in Loyola et al. (2011). Refer to this paper for further details on the algorithm and the 
validation of the total ozone column against ground-based instruments.

Within the framework of the O3M-SAF project, the Laboratory of Atmospheric Physics (LAP) at Aristotle University of Thessaloniki, in collaboration with the Hellenic National Meteorological Service, has developed a total ozone validation facility for GOME-2 data (found at http://lap.physics. auth.gr/eumetsat/totalozone).

\subsection{The ground-based measurements}

Archived total ozone column measurements from the WMO/GAW network that are routinely deposited at the WOUDC in Toronto, Canada (http://www.woudc.org) were used as ground reference. The WOUDC archive contains total ozone column data mainly from Dobson and Brewer UV spectrophotometers and from M-124 UV filter radiometers. A well-maintained and calibrated Dobson spectrophotometer measures the ozone column with an estimated accuracy of $1 \%$ for direct Sun observations and 2-3\% for zenith sky or zenith cloud observations for Sun elevation higher than $15^{\circ}$. The Dobson spectrophotometer is a large and manually controlled two-beam instrument based on the differential absorption method in the ultraviolet Huggins band where ozone exhibits strong absorption features. The measurement principle relies on the ratio of the direct sunlight intensities at two standard wavelengths. Since 1957, Dobson spectrophotometers have been deployed operationally in a worldwide network. The Brewer grating spectrophotometer is in principle similar to the Dobson; however, it has an improved optical design and is fully automated. The ozone column abundance is determined from a combination of four wavelengths between $306 \mathrm{~nm}$ and $320 \mathrm{~nm}$. Since the 1980s, Brewer instruments are part of the ground-based networks as well. Most Brewers are single monochromators, but a small number of systems are double monochromators with improved stray light performance.

The WOUDC stations considered and the reasoning behind the particular selection of stations have already been presented in a series of validation papers, such as for the validation of ten years of GOME observations (Balis et al., 2007a), the OMI-TOMS and OMI-DOAS dataset (Balis et al., 2007b), a new version of the OMI-TOMS algorithm (Antón et al., 2010) and the GOME-2 validation (Loyola et al., 2011).

The selection investigation and criteria have been discussed in detail in Balis et al. (2007a, b). We offer here a brief summary for completeness. For each ground-based station, a series of statistics and plots were performed, separately for direct Sun measurements and zenith sky observations. Daily coincidences of the satellite pixel's central latitude and longitude falling within a $150 \mathrm{~km}$ radius of the ground station were found and used for the creation of monthly, seasonal and yearly time series and scatter plots. Since the WOUDC data are daily means, there is no temporal treatment of the satel- lite observations. The percentage of the relative differences between ground and satellite TOC is used as the comparative tool for the validation. The statistics are then performed on a per latitude belt basis, per hemisphere basis and per global basis, always keeping the two types of ground-based instruments separate and using only direct Sun observations, as the most reliable. In the following, per hemisphere and per global basis comparisons will be shown and discussed upon, for space reasons.

\section{Results and discussion}

In the following section, the long-term performance of GOME-2 total ozone columns will firstly be examined against that of the three instruments discussed above over the background of the Dobson and Brewer total ozone columns. In order to compare possible trends, features and regions of special interest, contour representations of the latitudinal variability of the differences against time are presented first. This will enable the pictorial identification of regions and times where each of the instruments might have faced issues, as well as the long-term stability of all total ozone column records. Secondly, the time series of the differences averaged over the Northern Hemisphere enables the study of the seasonality effects and possible trends. Thirdly, a contour representation of the differences as a function of SZA and season permits the identification of lingering SZA and seasonal dependencies and how these compare among the different algorithms and instruments.

At this point, we wish to mention a possible source for the differences between the Dobson and the Brewer comparisons shown later on in this paper. There exists an inherent deviation between the treatment of the ground-based measurements and the analysis of the satellite observations and that is the choice of ozone absorption cross sections; the groundbased data are analysed using the Bass and Paur (1985), ozone cross sections, whereas with the GDP 4.x family of algorithms, cross sections measured with each instrument are used, namely the GOME measured flight model cross sections for $\mathrm{O}_{3}$, known as the GOME FM98 data (Burrows et al., 1999b) for the GOME and GOME-2 instruments and the SCIAMACHY flight model data (SFM) (Bogumil et al., 2003) for the SCIAMACHY instrument. The exception is TOMS V8 which uses, to the best of our knowledge, the Bass and Paur (1985) cross sections. It certainly falls within the plans for the next generation of algorithms, namely the GDP5.0 direct fitting algorithm, to harmonise the use of cross sections for the satellite observations. However this will come at a later stage. On the impact of the temperature, the point as we understand it is more whether some of the reported differences could come from the fact that ground-based datasets use cross sections at a fixed temperature (while temperature dependences are accounted for in satellite algorithms). We postulate that the answer is most 
probably yes, and it probably explains part of the different behaviour between Dobson and Brewer instruments as the Dobson measurements are more sensitive to temperature variations.

\subsection{Long-term stability}

\subsubsection{Latitudinal behaviour}

In Fig. 1 a contour representation of the difference between each of the four satellite instruments and the Dobson total ozone columns is shown in order to visualise the longterm picture of each instrument on a global scale and not only the coincidences to GOME-2. Hence, the stability of each instrument and algorithm behaviour may be examined. The comparative graphs are ordered from top to bottom in launch date from the one furthest back in time to the present. In order to create as homogeneous and hence comparable graphs as possible, these contour representations were created with a spread of 0.2 of the year (i.e. 1.5 months approximately) for the $\mathrm{x}$-axis and 30 degrees in latitude for the $y$-axis. The original data were averaged with a one-month spacing in time and 15 degrees in latitude. A common feature for all graphs that should be discussed here is the high negative values (more than $-2.5 \%$ ) around $15^{c}$ irc $\mathrm{N}$ which are due to the station of Bangkok, the sole station of the belt, which presents a near-constant ground-based overestimation from year 2005 onwards. This feature may appear more pronounced in some figures than others depending on the averaging/binning performed as needed. The station is not excluded from any comparisons.

In the upper left of Fig. 1, the near $15 \mathrm{yr}$ of GOME total ozone monitoring are presented with the large gaps in the Southern Hemisphere after year 2003 due to the ERS2 tape recorder failure. The gaps at the high latitudes, also noticeable for the other instruments, are due to the lack of ground-based stations, and not a satellite effect. A definite seasonal effect persists through the years with lows (underestimation) during the summer months for the Northern Hemisphere. The general picture appears to be that the GOME measurements oscillate between over- and underestimating the ground-based estimates between $-0.5 \%$ and $1 \%$ depending on the latitude belt and the season. This seasonal dependency northwards and southwards of $40^{\circ}$ has also been reported in Balis et al. (2007a) with an amplitude that does not exceed $1 \%-1.5 \%$ for the Dobson comparisons. In the upper right, a similar structure can be observed for the SCIAMACHY comparisons which start at the end of year 2002 with some instrumental issues still lingering appearing as the strong overestimations in all latitude bands for those months. From mid-2003 onwards, the northern middle latitudes demonstrate a seasonally affected underestimation of around $-1.5 \%$ whose amplitude also shows interannual variability, whereas the southern middle and high latitudes overestimate by around $1 \%$. These findings agree very well with the validation analysis presented in Lerot et al. (2009) even though the set of ground-based stations used there is not entirely the same as the one used in this study. In the middle left panel, the OMI_TOMS comparisons display the most homogeneous character of all instruments, with values that revolve around the zero difference (light green colours denote $\pm 0.5 \%$ ), no spikes at the high latitudes and a persistent slight underestimation above $30^{\circ}-60^{\circ} \mathrm{N}$. A different picture in the middle right panel for the OMI_DOAS comparisons presents the largest overestimates by $2-4 \%$ compared to the ground truth for the high latitudes of both hemispheres for the summer months, underestimates for the winter months and in general shows a variable structure with problems for high SZA cases as well. There appears also to be a general change in the comparative behaviour between ground and OMIDOAS from year 2009 which is shown more prominently in the time series plots presented below, a feature also observed for the Brewer comparisons (not shown here). These findings agree well with Balis et al. (2007b), who found the OMI-TOMS data product of high overall quality with no significant dependence on solar zenith angle or latitude. They showed as well that the OMI-DOAS data product systematically overestimated the total ozone values in the high latitudes of the Southern Hemisphere as well as a significant dependence on solar zenith angle. Finally, in the lower panel, GOME-2 exhibits a similar behaviour as GOME and SCIAMACHY with the seasonal alteration between overand underestimating in the mid- to high latitudes. As shown also in Loyola et al. (2011), the GOME-2 total ozone data obtained with GDP 4.4 slightly underestimate ground-based ozone by about $0.5 \%$ to $1 \%$ over the middle latitudes of the Northern Hemisphere and slightly overestimate by around $0.5 \%$ over the middle latitudes in the Southern Hemisphere.

\subsubsection{Long-term stability}

Focusing on the time series of the differences as a mean over the NH stations, in Fig. 2 the time evolution of the behaviour of each instrument is shown, alongside the standard deviation of the daily points which are included in the monthly mean value. In the same order as before, the GOME differences are shown in the upper left with the obvious seasonality with peak-to-peak that revolves around the zero line. SCIAMACHY, in the upper right, shows exactly the same patterns as GOME, whereas the OMI_TOMS differences in the middle left show a more or less flat behaviour as the years progress revolving around a mean of $-1 \%$ and no pronounced seasonal effects. OMI_DOAS follows the GOME and SCIAMACHY seasonality peaks until mid-2009 where the differences show a noticeable change from revolving around the zero line to an overestimation of between 1 and $2 \%$. The GOME-2 picture is very similar to that of the rest of the total ozone retrievals using the DOAS algorithm, apart from the fact that the seasonal peak-to-peak differences go from $-2 \%$ to $0 \%$. The seasonality effect apparent in 

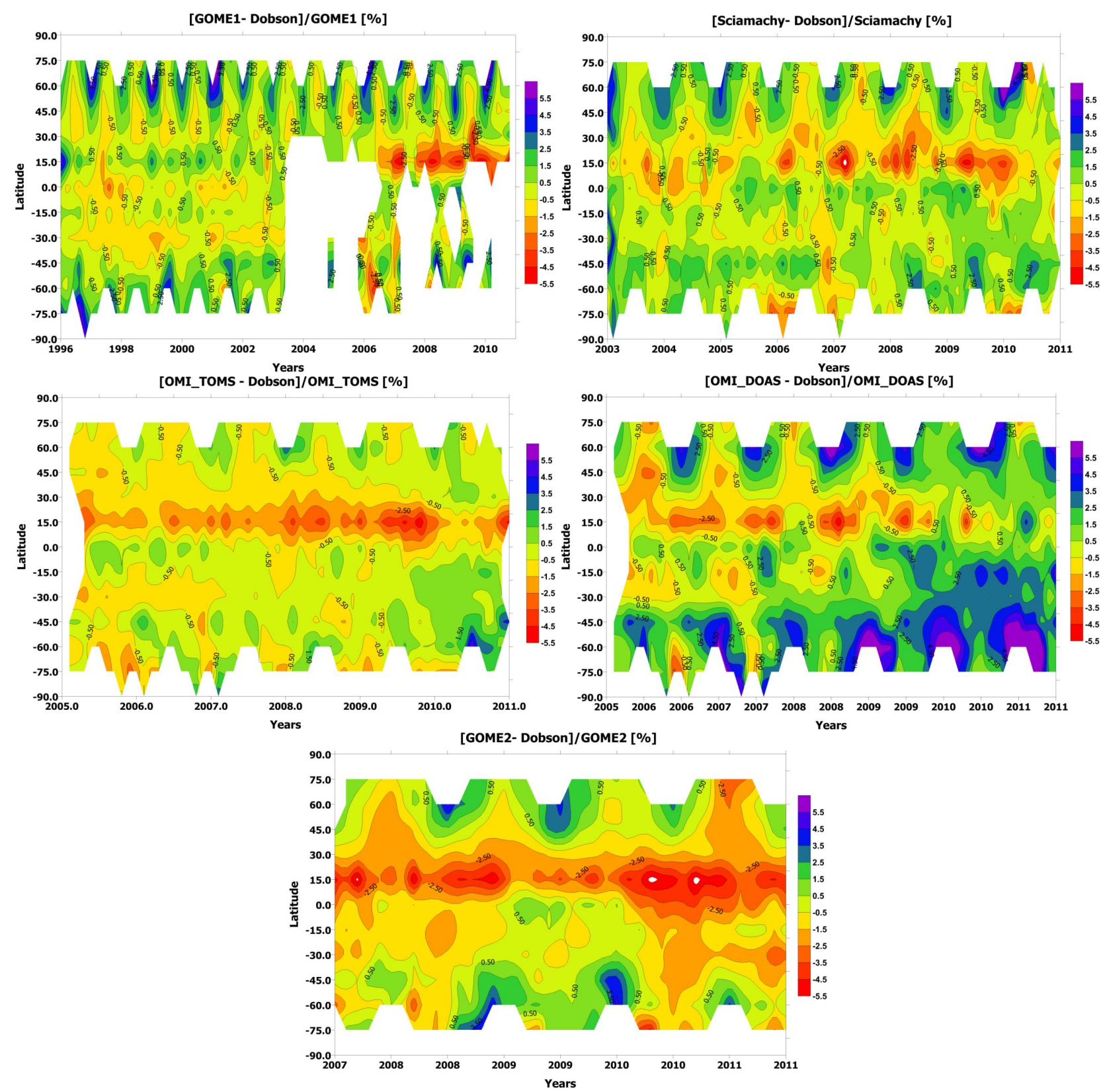

Fig. 1. Contour representation of the difference between satellite and Dobson ground-based measurements for the five datasets discussed in this paper as a function of latitude and time. Top left: GOME. Top right: SCIAMACHY. Middle left: OMI_TOMS. Middle right: OMI_DOAS. Bottom: GOME-2.

all DOAS algorithms (i.e. in all datasets shown apart from OMI_TOMS) can, for most part, be attributed to the fact that the satellite algorithms account for differences in effective temperature, whereas the ground-based instruments use a constant temperature for the ozone cross sections. A secondary effect arises from the fact that the DOAS algorithms cannot fit well the observed features at high SZAs, which appears to be both a seasonal and geometrical issue.

\subsubsection{Seasonal variability}

Another way to discern possible issues is to investigate the contour representation of the differences on a seasonal basis, as presented in Fig. 3. The layout of this figure is as per the previous two figures. For the visualization needs of this figure, a 1/12 per annum radius in time was used as well as a 10-degree radius in latitude. In the upper left, the 16 years of GOME create a smooth and clear image, which shows that, for the northern middle and high latitudes, the 

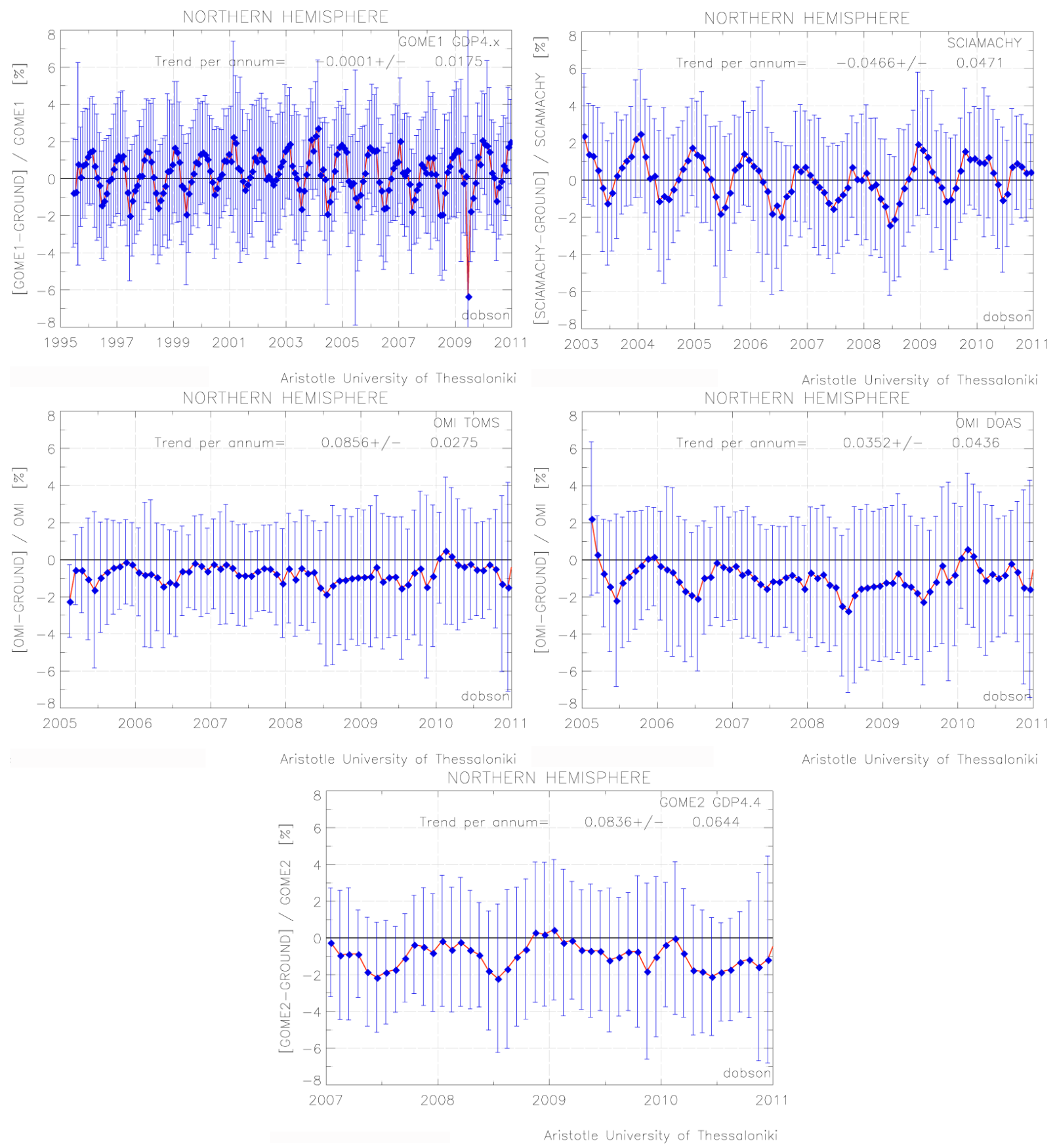

Fig. 2. Time series of the differences between satellite and Dobson ground-based measurements for the five datasets for the Northern Hemisphere stations only. Top left: GOME. Top right: SCIAMACHY. Middle left: OMI_TOMS. Middle right: OMI_DOAS. Bottom: GOME-2.

satellite overestimates by around $1 \%$ for the winter and autumn months and underestimates by the same amount for the summer months. The southern tropical belt around $20-30^{\circ}$ shows a zone of underestimation of $1 \%$, whereas, for the higher southern latitudes, the situation again reverses with a progressive increase in overestimation as the Antarctic stations are encountered which reaches the levels of 3 to $4 \%$.
This GOME overestimation in polar latitudes during winter can probably be reduced by applying GDP 4.4 (no addition of ghost column for snow/ice conditions). In the upper right, for SCIAMACHY, a similar picture is detected for the Northern Hemisphere albeit with more pronounced features: in the northern spring and summertime mid-latitudes, the underestimation reaches $-2 \%$, whereas the winter months also show 

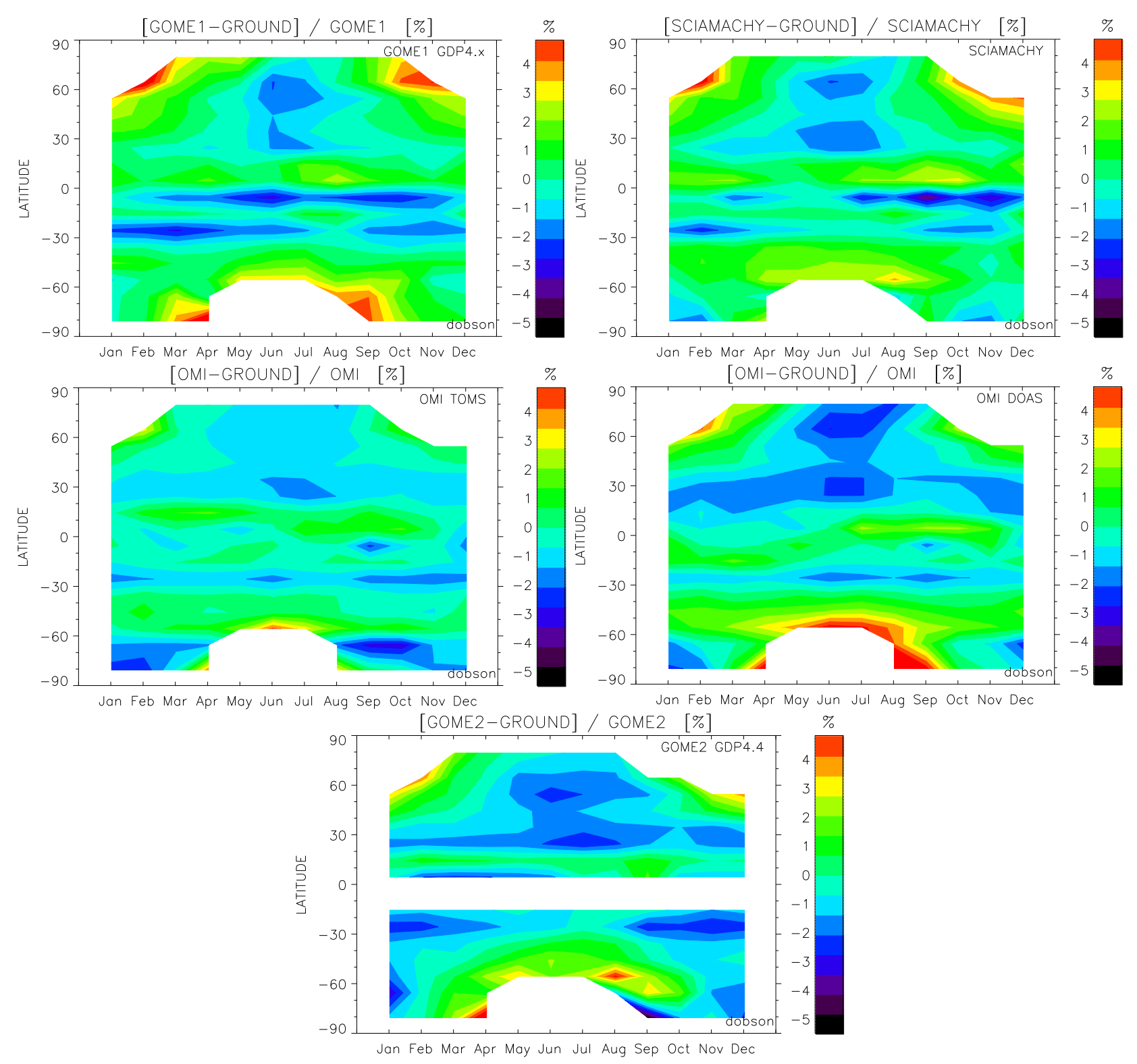

Fig. 3. Contour representation of the percentage differences between satellite and Dobson ground-based total ozone measurements depicted as a function of solar zenith angle and season. Top left: GOME. Top right: SCIAMACHY. Middle left: OMI_TOMS. Middle right: OMI_DOAS. Bottom: GOME-2.

higher overestimations. For the Southern Hemisphere, the pattern changes somewhat with the tropical zone overshooting by around $1 \%$ for all seasons and the middle and high latitudes overestimating up to $2-3 \%$ for the summer months and underestimating by $1 \%$ for the winter ones. In the middle left, the OMI_TOMS shows no seasonal or SZA issues with a constant underestimation of $-0.5 \%$ for all months and latitudes. Conversely, in the middle right, OMI_DOAS shows a similar over- to underestimating pattern as SCIAMACHY with different amplitudes with, interestingly, quite high values reaching 3-4\% for the spring Antarctic region. Finally, in the lower left, GOME-2 shows a strong, around
$-2 \%$, underestimation for the tropical belt around $\pm 30^{\circ}$ for all seasons which persists for higher southern latitudes for the winter months. The equatorial belt missing from this plot is due to the fact that the stations that belong to that belt (i.e. Natal/Brazil, and Nairobi/ Kenya) provide data only up to 2004 and 2000 respectively.

\subsection{Joint analysis and intercomparison}

In the following section, the comparison between GOME-2 and the other four satellite datasets is demonstrated through a composite figure with eight panels that follow the same 

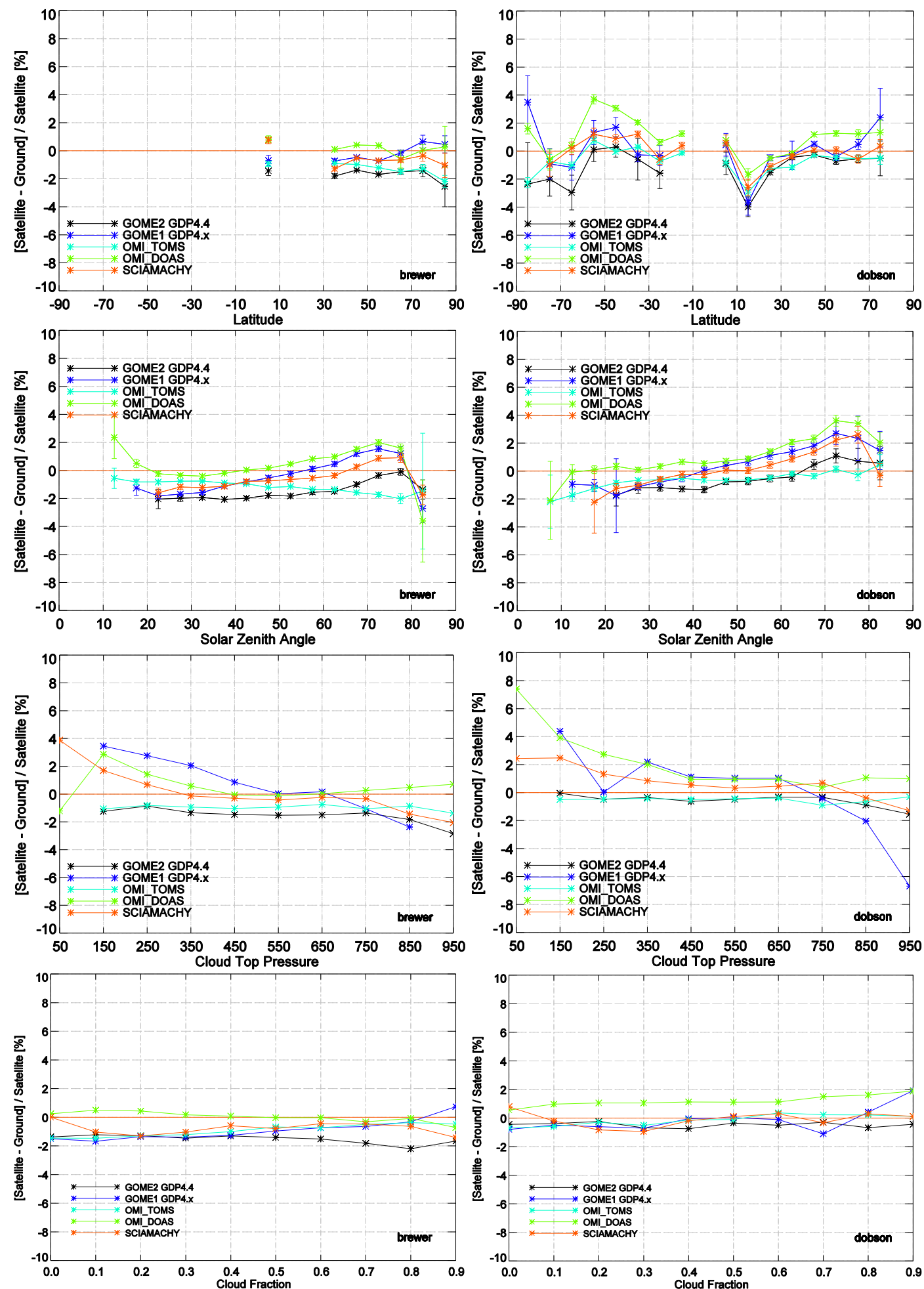

Fig. 4. Comparisons of GOME-2 (black), GOME-1 [dark blue], OMI-TOMS (light blue), OMI-DOAS (light green) and SCIAMACHY (orange) total ozone against the same ground-based measurements. Left column are the Brewer comparisons and the right column the Dobson comparisons. From top to bottom, the dependence of the percentage differences as function of latitude, solar zenith angle, cloud top pressure and cloud fraction. 
Table 2. The average differences between satellite and ground-based instruments for the five datasets shown in this paper. The mean and standard deviation for the latitudinal and the SZA variability are given for the Brewer instruments for low, middle and high latitudes and angles respectively.

\begin{tabular}{|c|c|c|c|c|c|c|}
\hline & \multicolumn{6}{|c|}{ Brewer } \\
\hline & \multicolumn{3}{|c|}{ Latitudinal variability } & \multicolumn{3}{|c|}{ SZA variability } \\
\hline & $\begin{array}{r}\text { Tropical } \\
\left(0-30^{\circ} \mathrm{N}\right)\end{array}$ & $\begin{array}{l}\text { Mid-Latitudes } \\
\left(30-60^{\circ} \mathrm{N}\right)\end{array}$ & $\begin{array}{r}\text { Polar } \\
\left(60-90^{\circ} \mathrm{N}\right)\end{array}$ & $\begin{array}{r}\text { Low } \\
\left(0-25^{\circ}\right)\end{array}$ & $\begin{array}{r}\text { Middle } \\
\left(25-70^{\circ}\right)\end{array}$ & $\begin{array}{r}\text { High } \\
\left(70-90^{\circ}\right)\end{array}$ \\
\hline GOME-2 & $-2.0 \pm 2.4 \%$ & $-1.9 \pm 2.4 \%$ & $-1.5 \pm 3.0 \%$ & $-2.1 \pm 2.4 \%$ & $-1.8 \pm 2.4 \%$ & $-0.4 \pm 3.2 \%$ \\
\hline GOME & $-1.7 \pm 2.6 \%$ & $-1.0 \pm 2.8 \%$ & $-0.02 \pm 3.4 \%$ & $-1.8 \pm 2.7 \%$ & $-0.6 \pm 2.8 \%$ & $1.1 \pm 3.5 \%$ \\
\hline OMI_TOMS & $-0.8 \pm 2.2 \%$ & $-1.0 \pm 2.1 \%$ & $-1.5 \pm 2.4 \%$ & $-0.8 \pm 2.1 \%$ & $-1.0 \pm 2.4 \%$ & $-1.1 \pm 4.3 \%$ \\
\hline OMI_DOAS & $-0.2 \pm 3.2 \%$ & $-0.02 \pm 2.9 \%$ & $-0.5 \pm 10.8 \%$ & $0.03 \pm 3.3 \%$ & $0.3 \pm 3.0 \%$ & $1.1 \pm 9.7 \%$ \\
\hline SCIAMACHY & $-1.3 \pm 2.8 \%$ & $-1.0 \pm 2.6 \%$ & $-0.6 \pm 3.0 \%$ & $-1.6 \pm 2.7 \%$ & $-0.8 \pm 2.6 \%$ & $0.3 \pm 3.5 \%$ \\
\hline
\end{tabular}

Table 3. The average differences between satellite and ground-based instruments for the five datasets shown in this paper. The mean and standard deviation for the latitudinal and the SZA variability are given for the Dobson instruments for low, middle and high latitudes and angles respectively.

\begin{tabular}{|c|c|c|c|c|c|c|}
\hline & \multicolumn{6}{|c|}{ Dobson } \\
\hline & \multicolumn{3}{|c|}{ Latitudinal variability } & \multicolumn{3}{|c|}{ SZA variability } \\
\hline & $\begin{array}{r}\text { Tropical } \\
\left(0-30^{\circ} \mathrm{N}\right)\end{array}$ & $\begin{array}{r}\text { Mid-Latitudes } \\
\left(30-60^{\circ} \mathrm{N}\right)\end{array}$ & $\begin{array}{r}\text { Polar } \\
\left(60-90^{\circ} \mathrm{N}\right)\end{array}$ & $\begin{array}{r}\text { Low } \\
\left(0-25^{\circ}\right)\end{array}$ & $\begin{array}{r}\text { Middle } \\
\left(25-70^{\circ}\right)\end{array}$ & $\begin{array}{r}\text { High } \\
\left(70--90^{\circ}\right)\end{array}$ \\
\hline GOME-2 & $-1.3 \pm 3.2 \%$ & $-0.9 \pm 2.7 \%$ & $-0.6 \pm 3.2 \%$ & $-1.7 \pm 3.2 \%$ & $-0.8 \pm 3.0 \%$ & $0.7 \pm 5.8 \%$ \\
\hline GOME & $-1.3 \pm 15.1 \%$ & $-0.4 \pm 10.3 \%$ & $0.6 \pm 4.0 \%$ & $-1.4 \pm 2.2 \%$ & $0.2 \pm 3.3 \%$ & $2.0 \pm 6.3 \%$ \\
\hline OMI_TOMS & $-0.9 \pm 3.3 \%$ & $-0.9 \pm 3.3 \%$ & $-0.5 \pm 3.0 \%$ & $-0.9 \pm 3.3 \%$ & $-0.5 \pm 3.0 \%$ & $0.06 \pm 3.8 \%$ \\
\hline OMI_DOAS & $-0.2 \pm 4.0 \%$ & $0.2 \pm 4.0 \%$ & $1.3 \pm 4.7 \%$ & $0.3 \pm 4.1 \%$ & $0.9 \pm 3.9 \%$ & $2.8 \pm 5.9 \%$ \\
\hline SCIAMACHY & $-1.1 \pm 3.6 \%$ & $-0.5 \pm 3.1 \%$ & $-0.4 \pm 3.8 \%$ & $-1.0 \pm 3.6 \%$ & $0.05 \pm 3.6 \%$ & $1.0 \pm 5.8 \%$ \\
\hline
\end{tabular}

colour-coding format. Common days of data between the GOME record and each of the other instruments are used. In the first row of Fig. 4, the percentage differences between satellite and co-located ground-based measurements have been grouped in $10^{\circ}$ bins in latitude. In the second row, the differences have been grouped in $5^{\circ}$ bins in solar zenith angle. In the third row, the cloud top pressure (CTP) dependency for each of the satellites is examined for bins of $50 \mathrm{mbar}$ and in the fourth and final row, the cloud fraction in bins of $5 \%$. These plots will be hereafter referred to as latitudinal variability, SZA variability, CTP variability and cloud fraction variability respectively.

For the case of the latitudinal variability and the Dobson comparisons (Fig. 4 top left), a very close agreement for the $\mathrm{NH}$ and the tropics is observed in the behaviour of all five algorithms up to $50^{\circ} \mathrm{N}$. From then and northwards, OMI_DOAS presents a steady 1-2\% overestimation and GOME deviates at the Arctic stations with an overestimation of more than $2 \%$. The other three algorithms present a very similar picture. In the $\mathrm{SH}$ the comparisons are more diverse: GOME is underestimating near $-0.5 \%$ around the Equator and tropics and reaching $-2 \%$ in the Antarctic. A very similar behaviour is observed by SCIAMACHY and
OMI_TOMS. OMI_DOAS is constantly overestimating by between 1 and $3 \%$, whereas GOME-2 shows a more constant behaviour around the zero line with the exception of the Antarctic where the differences reach $3 \%$. For the Brewer comparisons (Fig. 4 top right), the situation is more homogeneous with no latitudinal dependency seen in any of the algorithms and a mean of $-2 \%$ for GOME- 2 and OMI_TOMS, a mean around $-1 \%$ for GOME and SCIAMACHY and a mean of around zero for OMI_DOAS. This can be attributed to the fact that most Brewer stations fall around the middle latitude regions where the observational geometries and TOC ranges are far more favourable for constant, un-biased ground-based time series.

For the case of the SZA variability and the Dobson comparisons (second row left), all algorithms show a similar picture with underestimation for the low SZAs, overestimation for the high SZAs and an obvious SZA dependency. What differentiates one instrument from the other is the magnitude of the dependency; GOME-2 and OMI_TOMS show the least amount of dependency with values ranging between $-0.5 \%$ for the low and $0.5 \%$ for the high SZAs. OMI_DOAS seems to show the worst behaviour with a dependency that starts around $0 \%$ in difference and rises to $3 \%$ for SZAs higher 

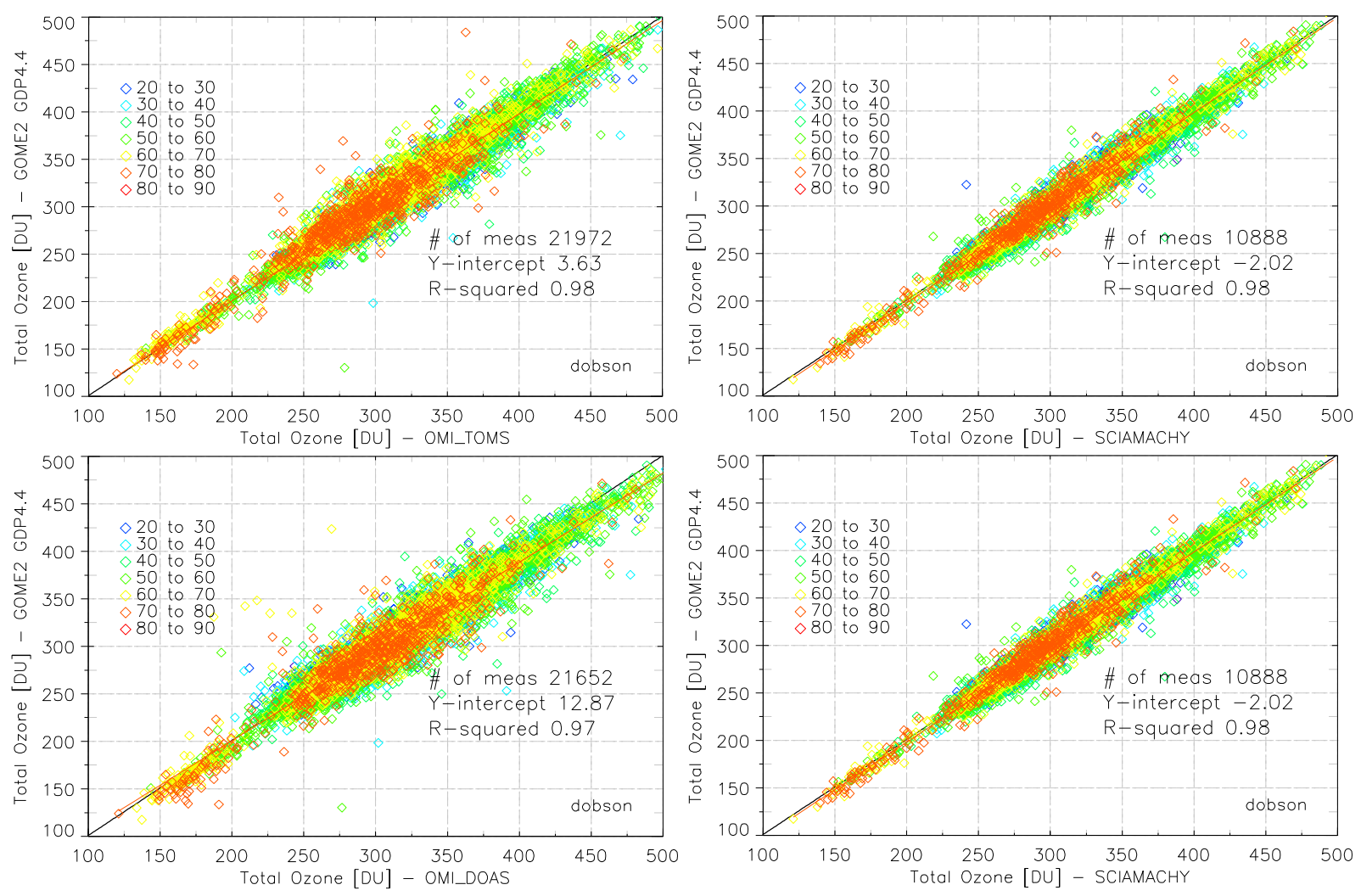

Fig. 5. Direct scatter plot comparisons of the satellite total column at the overpass sites for the Dobson ground-based stations. Top row: GOME-2 (on the y-axis) to GOME (left plot) and OMI_TOMS (right plot). Bottom row: GOME-2 (on the y-axis) to OMI_DOAS (left plot) and SCIAMACHY (right plot). The points are colour-coded according to the SZA related to that measurement. The r-squared and y-intercept of the scatter line (red) are also given.

than $80^{\circ}$. GOME and OMIDOAS demonstrate a dependency in between these two extremes. For the Brewer comparisons (second row right), all algorithms show the same mild positive dependency in SZA with differences that start around $-2 \%$ for the low SZA and rise to $0-2 \%$ for the high SZA, apart from OMI_TOMS which is showing a more stable albeit negative dependency between $-0.5 \%$ and $-2 \%$ for all SZAs.

For the case of the CTP variability and the Dobson comparisons (third row left), GOME-2 and OMI_TOMS show no dependency whatsoever and average values around $0 \%$. SCIAMACHY shows a mild negative dependency, moving from a $2 \%$ overestimation for low CTP to a $-1 \%$ underestimation for high CTP. GOME and OMI_DOAS show the strongest dependencies with averages ranging between $4 \%$ and $-2 \%$. For the Brewer comparisons (third row right), a near-exact situation can be seen. A point to consider when examining the very low $[<200 \mathrm{mbar}]$ and very high [> $800 \mathrm{mbar}$ CTP cases is the amount of data points that have been used in these graphs where, for example for the case of the GOME measurements, only 25 points make up the $200 \mathrm{mbar}$ bin, 60 the $300 \mathrm{mbar}$ bin, whereas there exist around 600 points for the $800 \mathrm{mbar}$ bin.
For the case of the cloud fraction variability and the Dobson comparisons (bottom left), there are no dependency and near-zero comparative values for all satellites apart from OMI_DOAS which shows a constant $1 \%$ positive offset for all cloud fractions. A near-similar picture for the Brewer comparisons with all algorithms around shows the $-1 \%$ negative offset.

The comparisons as function of CTP variability and cloud fraction variability agree well with the results from Antón and Loyola (2011).

In Tables 2 and 3, some statistics for the differences between satellite and ground-based measurements are given for distinct cases of latitudinal and SZA belts. In particular, three latitude bands are shown: the tropical zone, from $0^{\circ}$ to $30^{\circ} \mathrm{N}$; a middle latitude one, from $30^{\circ}$ to $60^{\circ} \mathrm{N}$; and a polar one, from $60^{\circ}$ to $90^{\circ} \mathrm{N}$, as well as three SZA bands: low SZA, from $0^{\circ}$ to $25^{\circ}$; middle SZA from $25^{\circ}$ to $70^{\circ}$; and high SZA from $70^{\circ}$ to $90^{\circ}$. Table 2 shows the statistics for the Brewers and Table 3 the statistics for the Dobson instruments. The seemingly high standard deviation is due to the fact that raw daily measurements were used for these statistics and not already binned, and hence smoothed out, data. 
Delving deeper into the comparative behaviour of the GOME-2 ozone record compared to the other algorithms, the direct scatter plots of the common data points between the satellites for the Dobson locations only are given in Fig. 5. With GOME-2 always on the y-axis, the scatter against GOME is shown in the upper left, OMI_TOMS in the upper right, OMI_DOAS in the lower left and SCIAMACHY in the lower right. The different colours denote the SZA values associated with the total ozone columns. The first point to note is the excellent correlation level which in all cases has an $R^{2}$ of 0.98 and the data points in all cases fall nicely in the $y=x$ line. No obvious dependency of the total ozone columns on the SZA can be seen. For the high SZAs (orange colour) associated with the low Antarctic total ozone values, the GOME-2 data underestimate the GOME and OMI_DOAS data, while agreeing well with OMI_TOMS and SCIAMACHY. The least deviation from the $y=x$ line can be seen in the comparisons with GOME (upper left) and the highest with OMI_DOAS (lower left). In the OMI_DOAS comparisons, numerous outlier points are observed irrespective of the associated SZA which points to the fact that the reason behind the disagreement is not due to the SZA treatment of the algorithms.

\section{Summary and conclusions}

In the current paper, we have assessed the stability and compatibility of five years of Global Ozone Monitoring Experiment-2/Metop-A total ozone columns against that of GOME/ERS, OMI/Aura and SCIAMACHY/ENVISAT through an extensive inter-comparison and validation exercise using as reference Brewer and Dobson ground-based measurements. Over the background truth of the groundbased measurements, the total ozone columns are interevaluated using a suite of established validation techniques and the main findings follow:

1. On average, GOME-2 data underestimate GOME data by about $0.80 \%$, and underestimate SCIAMACHY data by $0.40 \%$. There is no seasonal dependence of the differences between GOME-2, GOME and SCIAMACHY. The latter is expected since the three data sets are based on similar algorithms (GDP 4.x). This underestimation of GOME-2 is within the uncertainty of reference ground-based data used in the comparisons.

2. On average, GOME-2 data show no dependency with respect to the cloud top pressure and the cloud fraction, with discrepancies between the $-1 \%$ and zero levels. The same picture is observed for the OMI_TOMS data. The rest of the algorithms show varying levels of dependency, especially for high clouds, bearing in mind the sparsity of data at the low cloud top pressure values.

3. On average, GOME-2 data show very little SZA dependency and only for angles larger than $75^{\circ}$, maintain- ing a constant bias compared to the ground-based data. Marked is the improvement over the GOME dataset.

4. On average, GOME-2 data underestimate OMIDDOAS (collection 3) data by $1.28 \%$, without any significant seasonal dependence of the differences between them. The lack of seasonality might be expected since both GDP 4.4 and OMI_DOAS are DOAS-type algorithms and both consider the variability of the stratospheric temperatures in their retrievals.

5. On average, GOME-2 data and OMI_TOMS (collection 3) data have almost no bias (GOME-2 underestimates by $0.10 \%)$.

6. Overall, GOME-2 total ozone data agree at the $\pm 1 \%$ level with the standard ground-based measurements as well as other satellite instrument datasets and therefore are well suited to be incorporated and hence continue the satellite long-term global total ozone record needed among others for climate monitoring studies.

Acknowledgements. Development of the GOME-2 total ozone products and their validation has been funded by the O3MSAF project with EUMETSAT and national contributions. The GOME/ERS-2 and SCIAMACHY/ENVISAT products were generated at DLR under the auspices of the D-PAF/D-PAC project funded by ESA, the OMI/Aura products were provided by NASA and KNMI. Ground-based data used in this work were taken from the World Ozone and Ultraviolet Data Centre (WOUDC, http://www.woudc.org).

Edited by: P. Stammes

\section{References}

Antón, M., and Loyola, D.: Influence of cloud properties on satellite total ozone observations, J. Geophys. Res., 116, D03208, doi:10.1029/2010JD014780, 2011.

Antón, M., Koukouli, M. E., Kroon, M., McPeters, R. D., Labow, G. J., Balis, D., and Serrano, A.: Global validation of empirically corrected EP-Total Ozone Mapping Spectrometer (TOMS) total ozone columns using Brewer and Dobson ground-based measurements, J. Geophys. Res., 115, D19305, doi:10.1029/2010JD014178, 2010.

Balis, D., Kroon, M., Koukouli, M. E., Brinksma, E. J., Labow, G., Veefkind, J. P., and McPeters, R. D.: Validation of Ozone Monitoring Instrument total ozone column measurements using Brewer and Dobson spectrophotometer ground-based observations, J. Geophys. Res., 112, D24S46, doi:10.1029/2007JD008796, 2007a.

Balis, D., Lambert, J.-C., Van Roozendael, M., Loyola, D., Spurr, R., Livschitz, Y., Valks, P., Ruppert, T., Gerard, P., Granville, J., and Amiridis, V.: Ten years of GOME/ERS2 total ozone dataThe new GOME data processor (GDP) version 4: 2. Groundbased validation and comparisons with TOMS V7/V8, J. Geophys. Res., 112, D07307, doi:10.1029/2005JD006376, $2007 \mathrm{~b}$. 
Bass A. M., and Paur, R. J.: The ultraviolet cross-sections of ozone: I. The measurements in Atmospheric ozone, edited by: Zerefos, C. S. and Ghazi, A., Reidel, Dordrecht, Boston, Lancaster, 606610,1985

Bhartia, P. K., Wellemeyer, C. G., Taylor, S. L., Nath, N., and Gopolan, A.: Solar backscatter ultraviolet (SBUV) version 8 profile algorithm, in Proceedings of the Quadrennial Ozone Symposium, Kos, Greece, 1-8 June 2004, 295-296, 2004.

Bogumil, K., Orphal, J., Homann, T., Voigt, S., Spietz, P., Fleischmann, O. C., Vogel, A., Hartmann, M., Bovensmann, H., Frerick, J., and Burrows, J. P.: Measurements of molecular absorption spectra with the SCIAMACHY pre-flight model: instrument characterization and reference data for atmospheric remote sensing in the 230-2380 nm region, J. Photochem. Photobiol. A., 157, 167-184, 2003.

Bovensmann, H., Burrows, J., Buchwitz, M., Frerick, J., Noël, S., Rozanov, V. V., Chance, K. V., and Goede, A. P. H.: SCIAMACHY: Mission objectives and measurement modes, J. Atmos. Sci., 56, 127-150, 1999.

Burrows, J., Weber, M., Buchwitz, M., Rozanov, V., LadstätterWeißenmayer, A., Richter, A., DeBeek, R., Hoogen, R., Bramstedt, K., Eichmann, K.-U., Eisinger, M., and Perner, D.: The Global Ozone Monitoring Experiment (GOME): Mission concept and first scientific results, J. Atmos. Sci., 56, 151-175, 1999a.

Burrows, J., Richter, A., Dehn, A., Deters, B., Himmelmann, S., Voigt, S., and Orphal, J.: Atmospheric remote sensing reference data from GOME: Part 2. Temperature-dependent absorption cross-sections of $\mathrm{O}_{3}$ in the 231-794 nm range, J. Quant. Spectrosc. Radiat. Transfer, 61, 509-517, 1999 b.

Lerot, C., Van Roozendael, M., van Geffen, J., van Gent, J., Fayt, C., Spurr, R., Lichtenberg, G., and von Bargen, A.: Six years of total ozone column measurements from SCIAMACHY nadir observations, Atmos. Meas. Tech., 2, 87-98, doi:10.5194/amt-287-2009, 2009.
Levelt, P. F., van den Oord, G. H. J., Dobber, M. R., Malkki, A., Visser, H., de Vries, J., Stammes, P., Lundell, J. O. V., and Saari, H.: "The Ozone Monitoring Instrument", IEEE Trans. Geosci. Remote Sens., 44, 1093-1101, 2006.

Loyola, D. G., Koukouli, M. E., Valks, P., Balis, D. S., Hao, N., Van Roozendael, M., Spurr, R. J. D., Zimmer, W., Kiemle, S., Lerot, C., and Lambert, J.-C.: The GOME-2 total column ozone product: Retrieval algorithm and ground-based validation, J. Geophys. Res., 116, D07302, doi:10.1029/2010JD014675, 2011

Munro, R., Eisinger, M., Anderson, C., Callies, J., Corpaccioli,E., Lang, R., Lefebvre, A., Livschitz, Y., and Perez Albinana, A. GOME-2 on METOP: From in-orbit verification to routine operations, paper presented at EUMETSAT Meteorological Satellite Conference, Helsinki, Finland, 12-16 June, 2006.

Schoeberl, M., Douglass, A., Hilsenrath, E., Bhartia, P. K., Beer, R., Waters, J. W., Gunson, M., Froidevaux, L., Gille, J., Barnett, J., Levelt, P., and DeCola, P.: Overview of the EOS Aura Mission, IEEE Trans. Geosci. Remote Sens., 44, 1066-1074, doi:10.1109/TGRS.2005.861950, 2006.

Valks P., Loyola, D., Hao, N., Rix, M., and Slijkhuis, S.: Algorithm Theoretical Basis Document for GOME-2 Total Column Products of Ozone, $\mathrm{NO}_{2}$, tropospheric $\mathrm{NO}_{2}, \mathrm{BrO}, \mathrm{SO}_{2}, \mathrm{H}_{2} \mathrm{O}, \mathrm{HCHO}$, OClO and Cloud Properties, DLR/GOME-2/ATBD/01, Iss/Rev: 2/E, http://atmos.caf.dlr.de/gome2/docs/DLR_GOME-2_ATBD. pdf, last access: 15 December, 2011.

Van Roozendael, M., Loyola, D., Spurr, R., Balis, D., Lambert, J.-C., Livschitz, Y., Valks, P., Ruppert, T., Kenter, P., Fayt, C., and Zehner, C.: Ten years of GOME/ERS-2 total ozone data-The new GOME data processor (GDP) version 4: 1. Algorithm description, J. Geophys. Res., 111, D14311, doi:10.1029/2005JD006375, 2006.

Veefkind, J. P., de Haan, J. F., Brinksma, E. J., Kroon, M., and Levelt, P. F.: Total Ozone from the Ozone Monitoring Instrument (OMI) Using the DOAS technique, IEEE Trans. Geosci. Remote Sens., 44, 1239-1244, doi:10.1109/TGRS.2006.871204, 2006. 